University of South Florida

DIGITAL COMMONS

Digital Commons @ University of

@ UNIVERSITY OF SOUTH FLORIDA

South Florida

$5-2008$

\title{
Changes of Temperature and Bio-optical Properties in the South China Sea in Response to Typhoon Lingling, 2001
}

\author{
Shaoling Shang \\ Xiamen University
}

$\mathrm{Li} \mathrm{Li}$

Third Institute of Oceanography, State Oceanic Administration

Fengqin Sun

Xiamen University

Jingyu Wu

Xiamen University

Chuanmin $\mathrm{Hu}$

University of South Florida, huc@usf.edu

See next page for additional authors

Follow this and additional works at: https://digitalcommons.usf.edu/msc_facpub

Part of the Life Sciences Commons

\section{Scholar Commons Citation}

Shang, Shaoling; Li, Li; Sun, Fengqin; Wu, Jingyu; Hu, Chuanmin; Chen, Dewen; Ning, Xiuren; Qiu, Yun; Zhang, Caiyun; and Shang, Shaoping, "Changes of Temperature and Bio-optical Properties in the South China Sea in Response to Typhoon Lingling, 2001" (2008). Marine Science Faculty Publications. 1874. https://digitalcommons.usf.edu/msc_facpub/1874

This Article is brought to you for free and open access by the College of Marine Science at Digital Commons @ University of South Florida. It has been accepted for inclusion in Marine Science Faculty Publications by an authorized administrator of Digital Commons @ University of South Florida. For more information, please contact digitalcommons@usf.edu. 


\section{Authors}

Shaoling Shang, Li Li, Fengqin Sun, Jingyu Wu, Chuanmin Hu, Dewen Chen, Xiuren Ning, Yun Qiu, Caiyun Zhang, and Shaoping Shang 


\title{
Changes of temperature and bio-optical properties in the South China Sea in response to Typhoon Lingling, 2001
}

\author{
Shaoling Shang, ${ }^{1}$ Li Li, ${ }^{2}$ Fengqin Sun, ${ }^{1}$ Jingyu Wu, ${ }^{1}$ Chuanmin $\mathrm{Hu},{ }^{3}$ Dewen Chen, ${ }^{1}$ \\ Xiuren Ning, ${ }^{4}$ Yun Qiu, ${ }^{2}$ Caiyun Zhang, ${ }^{1}$ and Shaoping Shang ${ }^{1}$ \\ Received 1 February 2008; revised 21 March 2008; accepted 2 April 2008; published 20 May 2008.
}

[1] A large patch of enhanced chlorophyll a concentration (Chla), lower sea surface temperature (SST), and lower sea surface height $(\mathrm{SSH})$ was revealed in the central South China Sea (SCS) in November 2001 after the passage of typhoon Lingling. Maximum SST reduction of $11^{\circ} \mathrm{C}$ occurred one day after Lingling's passage on 11/11. Subsequently, against a background level of $0.08 \mathrm{mg} / \mathrm{m}^{3}$, average Chla within the area of $12.60-16.49^{\circ} \mathrm{N}, 112.17-$ $117.05^{\circ} \mathrm{E}$ increased to $0.14 \mathrm{mg} / \mathrm{m}^{3}$ on $11 / 12$ and then to $0.37 \mathrm{mg} / \mathrm{m}^{3}$ on $11 / 14$. Dissolved organic matter and detritus were differentiated from Chla using a recent bio-optical algorithm. They contributed $64 \%$ to the increase of total absorption immediately after Lingling, while most of the changes later $(74 \%)$ were due to phytoplankton. The area under Lingling's impact covered ca. $3^{\circ}$ latitude and $4^{\circ}$ longitude, which is much greater than the two summer cases previously observed in the northern SCS. This event lasted for ca. 15 days, and resulted in carbon fixation in the order of $0.4 \mathrm{Mt}$. Such a drastic response was attributed to the coupling of typhoon-induced nutrient pumping with the pre-established cyclonic gyre in the central SCS driven by the prevailing northeast monsoon. Citation: Shang, S., L. Li, F. Sun, J. Wu, C. Hu, D. Chen, X. Ning, Y. Qiu, C. Zhang, and S. Shang (2008), Changes of temperature and bio-optical properties in the South China Sea in response to Typhoon Lingling, 2001, Geophys. Res. Lett., 35, L10602, doi:10.1029/ 2008GL033502.

\section{Introduction}

[2] Some tropical cyclones have shown great impacts on primary production in the broad oligotrophic ocean, and thus on carbon cycling [e.g., Babin et al., 2004; Walker et al., 2005]. The South China Sea (SCS) is one of the largest semi-enclosed marginal seas subject to frequent tropical cyclones (typhoon hereafter, according to convention in the study region). Two cases of typhoonforced chlorophyll a (Chla) augmentation have been documented in the northern SCS. One was associated with typhoon Kai-Tak in July 2000, when an average of

\footnotetext{
${ }^{1}$ State Key Laboratory of Marine Environmental Science, Xiamen University, Xiamen, China.

${ }^{2}$ Third Institute of Oceanography, State Oceanic Administration, Xiamen, China.

${ }^{3}$ College of Marine Sciences, University of South Florida, St. Petersburg, Florida, USA.

${ }^{4}$ State Key Laboratory of Satellite Ocean Environment Dynamic Processes, State Oceanic Administration, Hangzhou, China.
}

30 -fold increase in the surface Chla was found during its three-day passage [Lin et al., 2003]. Another was induced by typhoon Damrey in September 2005, when a Chla peak of $4 \mathrm{mg} / \mathrm{m}^{3}$ was detected [Zheng and Tang, 2007]. All these studies were based mainly on satellite remote sensing. However, there was also strong argument that the observed changes in the oligotrophic ocean were not due to Chla but due to vertically mixed chromophoric dissolved organic matter (CDOM) from deeper depths, which has a higher absorption coefficient than the photochemically degraded $\mathrm{CDOM}$ within the undisturbed prestorm upper mixed layer [Hoge and Lyon, 2002]. In this study, we present observations of ocean responses in the SCS subsequent to the passage of typhoon Lingling in November 2001, which show strong surface cooling and large scale Chla enhancement in winter. In particular, we applied the most recent satellite algorithms to differentiate Chla explicitly from CDOM, thus removing the ambiguity of whether the observed change was due to phytoplankton or CDOM.

\section{Data}

[3] Daily TMI (the Tropical Rain Measuring Mission's microwave imager) sea surface temperatures (SSTs) were obtained from the Remote Sensing Systems Company. SeaWiFS (Sea-viewing Wide Field-of-view Sensor) L1A GAC data and L3 Chla derived from OC4 algorithm (OC4 Chla hereafter) were obtained from the NASA DAA $\overline{\mathrm{C}}$ and GSFC. $a_{\mathrm{ph}}(443)$ (phytoplankton absorption coefficient at $443 \mathrm{~nm}$ ) and $a_{\mathrm{dg}}(443)$ (CDOM and detritus absorption coefficient at $443 \mathrm{~nm}$ ) were derived from the SeaWiFS L1A data using the quasi-analytical algorithm (QAA) [Lee et al., 2002] and the SeaDAS software. Spatial resolution was $25 \times 25 \mathrm{~km}^{2}$ for SST and $9 \times$ $9 \mathrm{~km}^{2}$ for OC4_Chla, $a_{\mathrm{ph}}(443)$ and $a_{\mathrm{dg}}(443)$. Along track T/P (TOPEX/PŌSEIDON) gridded sea surface height and anomaly (SSHA) were obtained from NASA JPL. ARGO data collected at $12.71-12.84^{\circ} \mathrm{N}, 116.62-116.67^{\circ} \mathrm{E}$ were provided by the China Argo Real-time Data Center. Typical temperature and salinity profiles inside the winter gyre (see Section $4.1,15.00^{\circ} \mathrm{N}, 112.00^{\circ} \mathrm{E}$ and $15.00^{\circ} \mathrm{N}$, $113.00^{\circ} \mathrm{E}$ ) were obtained from one cruise conducted in December 1998. No simultaneous in situ $a_{\mathrm{ph}}$ and $a_{\mathrm{dg}}$ data in the study region was available until December 2006, which was then used as surrogate by assuming that temporal changes are dominated by seasonal patterns rather than by interannual variations for this oligotrophic ocean that is away from terrestrial discharge. The meas- 

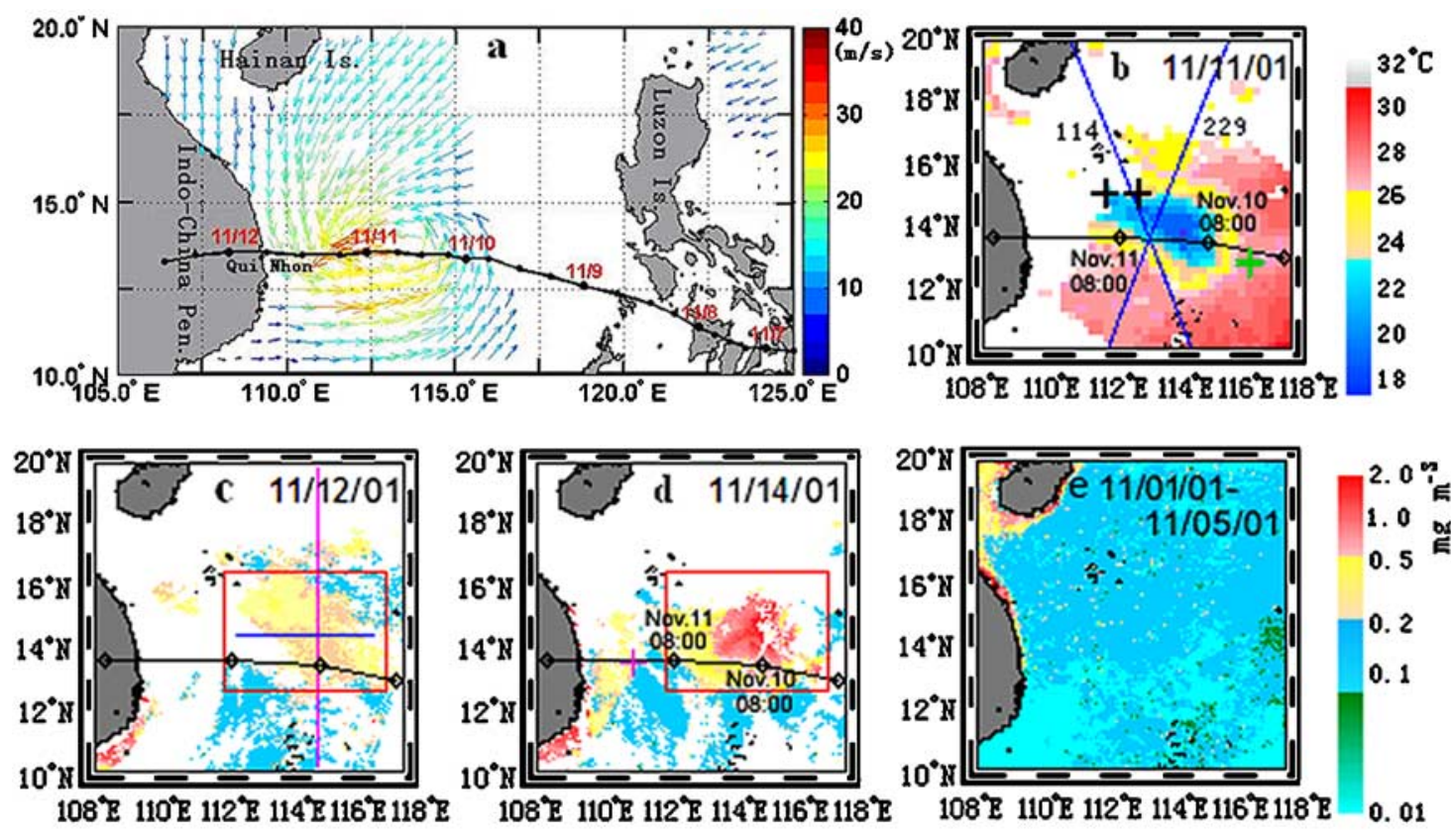

Figure 1. (a) QuikSCAT wind image on 11/11/2001 showing Lingling and the South China Sea. Lingling's 6-hour positions are shown as black dots, while the time of each annotated date is 08:00 local time. "Is." and "Pen." stand for island and peninsula, respectively. (b) TMI SST on 11/11. Black line shows the track of Lingling. (c) SeaWiFS OC4_Chla on $11 / 12$. Blue line: $14.4^{\circ} \mathrm{N}$; Purple line: $115.2^{\circ} \mathrm{E}$; Red square: area for estimates of the mean Chla. (d) SeaWiFS OC4_Chla on 11/14. (e) SeaWiFS OC4_Chla of 11/1-11/5 (before Lingling).

urements of $a_{\mathrm{ph}}$ and $a_{\mathrm{dg}}$ were detailed by Hong et al. [2005] and Wu et al. [2007].

\section{Results}

\subsection{Surface Response}

[4] Typhoon Lingling originated in the Philippine Sea on $11 / 6 / 2001$. It entered the SCS as a weak tropical storm on $11 / 9$ (Figure 1a) and moved slowly at $\sim 4.6-5.1 \mathrm{~m} / \mathrm{s}$. Then, it intensified rapidly, with wind speed increased from 65 to 100 knots, and traversed the mid-basin of the SCS as a category 4 typhoon (on the Saffir-Simpson hurricane scale) during $11 / 9$ to $11 / 12$. Maximum wind was $110-115$ knots on 11/10 and 11/11. It made landfall near Qui Nhon (Figure 1a) on 11/12, producing heavy rainfall and high winds over the central Indo-China Peninsula (http:// metocph.nmci.navy.mil).

[5] Prior to Lingling, SST was $27.0 \sim 30.0^{\circ} \mathrm{C}$ in the study region of $10 \sim 20^{\circ} \mathrm{N}, 110 \sim 118^{\circ} \mathrm{E}$. Shortly after Lingling's passage, significant cooling occurred on 11/11 over an area of $\sim 150,000 \mathrm{~km}^{2}$ between $12.60-16.50^{\circ} \mathrm{N}, 112.20-$ $117.00^{\circ} \mathrm{E}$ (Figure $1 \mathrm{~b}$ ), with SST dropped to $17.4 \sim 26.0^{\circ} \mathrm{C}$. On average, SST dropped $5.5^{\circ} \mathrm{C}$ with respective maxima of $11^{\circ} \mathrm{C}$. The location of the cooling was to the right of the typhoon track, consistent with previous studies [e.g., Price, 1981]. However, cooling of such magnitude $\left(11^{\circ} \mathrm{C}\right)$ has not been reported previously. For example, typhoon-induced maximum cooling was $9^{\circ} \mathrm{C}$ in July [Lin et al., 2003] and $5^{\circ} \mathrm{C}$ in September [Zheng and Tang, 2007] in the northern SCS, and $7^{\circ} \mathrm{C}$ in the Gulf of Mexico [Walker et al., 2005].

[6] Coinciding with the cooling, SeaWiFs images showed enhancement of OC4_Chla on 11/12 and 11/14 (Figures 1c and 1d). Prior to this event, surface OC4_Chla was predominantly $0.1 \mathrm{mg} / \mathrm{m}^{3}$, typical for the $\mathrm{SCS}$
(Figure 1e). Higher OC4_Chla values were found from the coast of Vietnam to the mid-basin. The coastal areas were not included in the analysis of typhoon-induced changes because they were likely associated with coastal currents or runoff. Our study focus is therefore bounded to the area east of $112^{\circ} \mathrm{E}$.

[7] The high OC4_Chla patch, with the mean value of $>0.2 \mathrm{mg} / \mathrm{m}^{3}$, covere $\sim 130,000 \mathrm{~km}^{2}$ on $11 / 12$, and was maintained at a similar size until 11/14. Within the rectangular region (red square in Figures $1 \mathrm{c}$ and 1d), both $a_{\mathrm{ph}}(443)$ and $a_{\mathrm{dg}}(443)$ derived from the QAA increased significantly after Lingling's passage (Figure 2a). $a_{\mathrm{ph}}(443)$ increased by $75 \%$ on $11 / 12$, compared to initial conditions before Lingling (11/1-11/5 composite), and $a_{\mathrm{dg}}(443)$ increased by $100 \%$. Two days later, the increase of $a_{\mathrm{ph}}(443)$ became four times of that of $a_{\mathrm{dg}}(443)(160 \%$ versus $38 \%)$. Their combined increase was $0.025 \mathrm{~m}^{-1}$ during the $1 \mathrm{st}$ phase (before 11/12), of which $64 \%$ was contributed by CDOM and detritus. During the 2nd phase (11/12-11/14), merely $26 \%$ of the combined increase $\left(0.046 \mathrm{~m}^{-1}\right)$ was from CDOM and detritus. Our results showed that although more than half of the immediate surface ocean color change was due to CDOM and detritus, most of the delayed changes were due to Chla. Because $a_{\mathrm{ph}}^{*}(443)$ (Chla-specific phytoplankton absorption) was $\sim 0.15 \mathrm{~m}^{2} / \mathrm{mg}$ in the study region in winter (J. Wu and S. Shang, manuscript in preparation, 2008), these changes in $a_{\mathrm{ph}}(443)$ were equivalent to Chla changes from $0.08 \mathrm{mg} / \mathrm{m}^{3}$ to $0.14 \mathrm{mg} / \mathrm{m}^{3}$, and then to $0.37 \mathrm{mg} / \mathrm{m}^{3}$. Hereafter these values, instead of OC4_Chla, were used to evaluate the impact of Lingling on phytoplankton production and carbon fixation.

[8] In addition to the surface cooling and Chla enhancement, there appeared temporal lag and spatial dislocation between the two responses. It took Lingling 24 hours from 

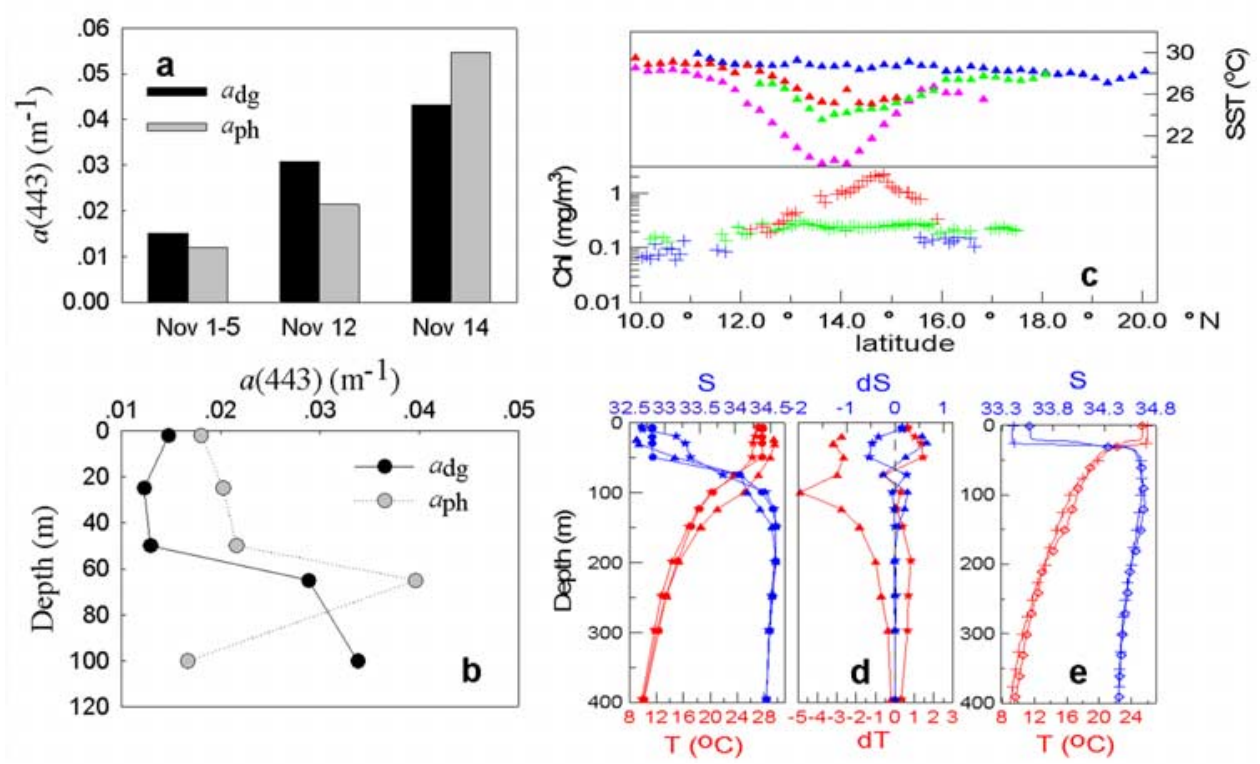

Figure 2. (a) Changes of SeaWiFS $a_{\mathrm{ph}}(443)$ and $a_{\mathrm{dg}}(443)$ after Lingling. (b) Vertical distribution of $a_{\mathrm{ph}}(443)$ and $a_{\mathrm{dg}}(443)$ in November 2006, where the sampling location is shown in Figure 1d as a purple cross-mark. (c) TMI SST and SeaWiFS OC4_Chla changes along $115.2^{\circ} \mathrm{E}$ in November 2001. Blue, 11/5; purple, 11/11; green, 11/12; and red, 11/14. (d) (left) vertical profiles of ARGO temperature (T, red) and salinity (S, blue) in November 2001, where the ARGO locations are shown in Figure 1b as green cross-marks. Triangle, 11/9; star, 11/16; and dot, 11/30. (right) Vertical profiles of ARGO temperature change (dT, red) and salinity change (dS, blue). Triangle, from 11/9 to 11/16; star,11/16 to 11/30. (e) Typical temperature ( $T$, red) and salinity (S, blue) profiles in the winter gyre in December 1998, where the CTD sampling locations are shown in Figure $1 \mathrm{~b}$ as black cross-marks. Cross, $15^{\circ} \mathrm{N}, 112^{\circ} \mathrm{E}$; diamond, $15^{\circ} \mathrm{N}, 113^{\circ} \mathrm{E}$.

$11 / 9$ to $11 / 10$ to traverse the area where surface cooling was observed immediately after. Then, as Figure 2c shows, SST gradually increased between $11 / 11$ and $11 / 14$. OC4_Chla peaked on 11/14, lagging minimum SST by 3 days and Lingling's departure by about 4 days. This is comparable to previous observations in the northern SCS [Zheng and Tang, 2007] and in the Gulf of Mexico [Walker et al., 2005].

\subsection{Response at Depth}

[9] ARGO profiles recorded at a corner of the cold patch and about $30 \mathrm{~km}$ apart from Lingling's track (Figure 1b) showed temperature $(\mathrm{T})$ and salinity $(\mathrm{S})$ contrast at depth before and after Lingling's passage (Figure 2d). Although there was no data in the upper $20 \mathrm{~m}$ before Lingling, the values of T and $\mathrm{S}$ measured at $23 \mathrm{~m}$ and $30 \mathrm{~m}$ were close to each other, suggesting that they were within the mixing layer and thus the mixed layer depth (MLD) was $\sim 30 \mathrm{~m}$. After Lingling, MLD deepened to $50 \mathrm{~m}$. T at $23 \mathrm{~m}$ decreased by $2.88^{\circ} \mathrm{C}$ from $11 / 9$ to $11 / 16$, similar to the average change of TMI SST of $2.2^{\circ} \mathrm{C}$ at the ARGO locations from $11 / 5$ to $11 / 11$. The influence was generally confined to the upper $300 \mathrm{~m}$, where $\Delta \mathrm{T}$ of -0.36 to $-4.89^{\circ} \mathrm{C}$ and $\Delta \mathrm{S}$ of -0.25 to +0.66 were detectable (Figure 2d).

\section{Discussion}

\subsection{Forcing}

[10] In general, the primary mechanisms accounting for typhoon-forced sea surface cooling are vertical mixing (entrainment), transient upwelling (Ekman pumping), and latent heat loss to the atmosphere [Price, 1981]. What favored Lingling, a category 4 typhoon, to cause the dramatic cooling $\left(11^{\circ} \mathrm{C}\right)$ ? Since the estimated latent heat loss it induced $\left(56 \sim 59 \mathrm{~m} / \mathrm{s}\right.$ wind) was $<500 \mathrm{w} / \mathrm{m}^{2}$, which yielded cooling $<3^{\circ} \mathrm{C}$ [Luis and Kawamura, 2000], mixing and upwelling were expected to play a critical role.

[11] The role of mixing and upwelling was examined using the ARGO profiles (Figure 2d). From 11/9 to 11/16, T dropped almost throughout the observed water column. S increased above $60 \mathrm{~m}$ where mixing dominated, and decreased slightly between $60 \mathrm{~m}$ and $80 \mathrm{~m}$ as a result of mixing. However, the magnitude of change was much smaller in this layer, suggesting that upwelling made a contribution. Below $85 \mathrm{~m}, \Delta \mathrm{S}$ became positive, indicating that more saline deep water was upwelled. Maximum $\Delta \mathrm{S}$ occurred at $100 \mathrm{~m}$ where minimum $\Delta \mathrm{T}$ was found, implying that upwelling dominated at $100 \mathrm{~m}$ and below. From 11/16 to $11 / 30$, the change patterns of $\mathrm{T}$ and $\mathrm{S}$ reversed (Figure 2d), suggesting recovery from Lingling's perturbations (mainly mixing and upwelling).

[12] What intensified the cooling effect of mixing and upwelling at the center of the cold patch? In the area of extreme cooling, T/P derived geopotential anomaly showed a pre-existing cyclonic gyre (Figure 3), which appear to be a sub-basin scale seasonal circulation driven by the winter monsoon [Li et al., 2000]. Maximum cooling was found at the gyre center $\left(\sim 14^{\circ} \mathrm{N}, 114^{\circ} \mathrm{E}\right.$; Figures 1 and 3$)$ where upward doming of isotherms occurred. Changes of alongtrack SSHA on Passes 114 and 229 (before and after Lingling) showed that maximum cooling of $\sim 10^{\circ} \mathrm{C}$ along these tracks was co-located with maximum SSHA change (Figure 3). Along Pass 114, minimum SST of $20.6^{\circ} \mathrm{C}$ occurred with minimum SSHA of $-28 \mathrm{~cm}$ at $14.4^{\circ} \mathrm{N}$ on 

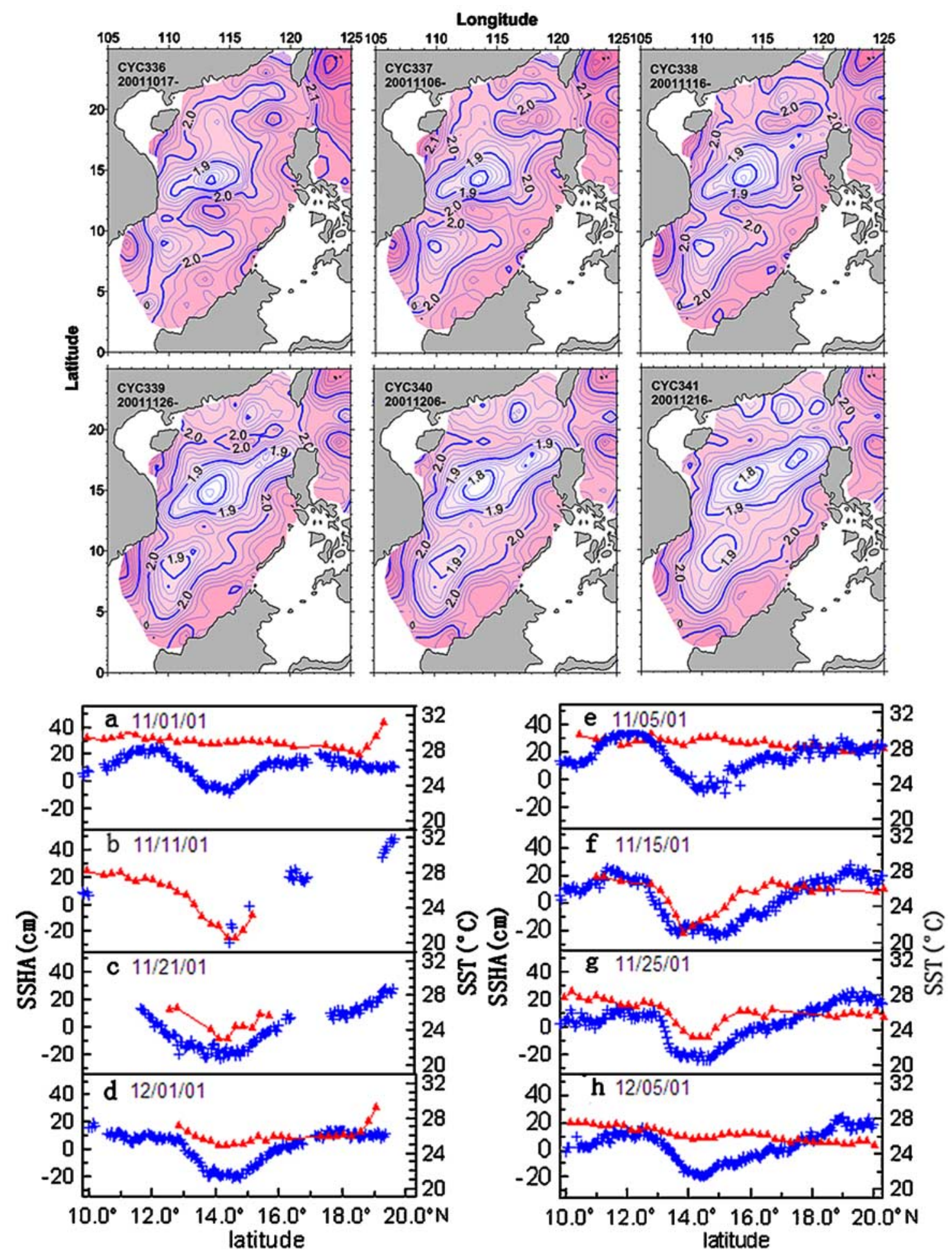

Figure 3. (top) $\mathrm{T} / \mathrm{P}$ surface dynamic heights from mid-October to mid-December (in dynamic meters). (bottom) Along track T/P SSHA on (a)-(d) Pass 114 and (e)-(h) Pass 229. Blue, SSHA; red, SST. Passes 114 and 229 are shown in Figure $1 \mathrm{~b}$ as blue lines.

11/11. The magnitude of cooling decreased with increasing SSHA. The maximum SSHA drop of $\geq 20 \mathrm{~cm}$ was similar to that detected within post-hurricane cold-core cyclones in the Gulf of Mexico [Walker et al., 2005]. In winter, the thermocline in the SCS is typically $50-100 \mathrm{~m}$ below the sea surface, which however domes up to $\sim 30 \mathrm{~m}$ at the gyre center (Figure 2e). Shallow mixed layer at the gyre center thus favored a more vigorous cooling (induced by mixing and upwelling) than the area outside of the gyre.

[13] Following Price et al. [1994], Babin et al. [2004], and Walker et al. [2005], the isopycnal displacement of the thermocline due to storm-induced upwelling can be com- 
puted based on maximum wind speeds of $110-115$ knots, $t$ values of $19.2 \mathrm{~N} / \mathrm{m}^{2}$, and a transit speed of $5 \mathrm{~m} / \mathrm{s}$. It was estimated that the scale of isopycnals displacement was about $100 \mathrm{~m}$, which was significant enough to pump waters below the thermocline to the surface. Using SSH data and the ARGO profiles, we also computed isotherm upwelling $(\Delta \eta)$ from the change in SSHA $(\Delta \mathrm{h})$ using the reduced gravity approximation $\Delta \eta=-\mathrm{g} / \mathrm{g}^{\prime} \Delta \mathrm{h}$ [Shay et al., 2000]. The estimated isopycnal displacement was about $50 \mathrm{~m}$ for the observed maximum $28 \mathrm{~cm}$ changes in SSHA. This is smaller than the estimate based on wind stress, probably because that the 10 day revisit of the $\mathrm{T} / \mathrm{P}$ altimeter is not sufficient to resolve short-term SSH changes. However, it consistently indicated that waters below the thermocline were upwelled to the surface.

[14] The same mechanism could explain the Chla enhancement. Typhoon-induced strong upwelling and mixing, together with eddy-pumping before Lingling, resulted in Chla enhancement from both upward entrainment of the deep Chla maxima [e.g., Walker et al., 2005] and new nutrient injection from the deeper water [Babin et al., 2004]. Phytoplankton is known to grow and divide rapidly with upwelled nutrients. However, nutrient-rich waters, once brought to the surface, advect away from the upwelling center. Therefore, phytoplankton tends to bloom off the upwelling center. Further, the amount of carbon fixed per unit time per unit Chla is lower than normal during upwelling [Mann and Lazier, 1996]. In addition, heavy cloudiness during the passage of the hurricane might limit production. The combined effect could explain why the temporal lag occurred between the surface cooling and Chla enhancement.

[15] The magnitude of Chla enhancement for Lingling was lower than those reported for Kai-Tak and Damrey [Lin et al., 2003; Zheng and Tang, 2007], which were from a band-ratio algorithm (OC4) that does not distinguish CDOM from Chla. But the area under influence was about $4 \sim 10$ times bigger for Lingling $\left(\sim\right.$ over $3^{\circ}$ latitude and $4^{\circ}$ longitude) than for those two.

\subsection{Chla or CDOM?}

[16] Most published reports on typhoon-induced changes attributed all color changes to biological activity. Using a linear matrix inversion model, Hoge and Lyon [2002] suggested that color changes in the oligotrophic oceans were solely due to CDOM, and not due to phytoplankton. Because of the deep nutricline, $H u$ and Muller-Karger [2007] showed one rare case that neither CDOM nor Chla increased after Hurricane Dennis (category 4) in the northern Gulf of Mexico in summer 2005. Here, we showed that the amount of CDOM and detritus mixed and advected upward was equal to that of Chla, but Chla increased more in the later phase after Lingling. The upward transport of CDOM and detritus was verified by $a_{\mathrm{ph}}(443)$ and $a_{\mathrm{dg}}(443)$ measurements in the study region in winter 2006 (Figure 2b). According to these profiles, that upward advection and mixing in the upper $100 \mathrm{~m}$ (where data were available) could lead to surface $a_{\mathrm{dg}}(443)$ of $\sim 0.03 \mathrm{~m}^{-1}$ and surface $a_{\mathrm{ph}}(443)$ of $\sim 0.02 \mathrm{~m}^{-1}$, which were consistent from those derived from the QAA algorithm. Indeed, the ability of the QAA algorithm to decouple phytoplankton and
$\mathrm{CDOM} /$ detritus has already been verified in an ocean gyre [Hu et al., 2006].

\subsection{Impact on Primary Production}

[17] The $\geq 2{ }^{\circ} \mathrm{C}$ cooling did not disappear until $11 / 20$, although the area decreased. Due to heavy cloud cover, it is not clear how long the enhanced Chla persisted. However, a patch of OC4_Chla $>0.2 \mathrm{mg} / \mathrm{m}^{3}$ was observed in the composite SeaWiFS image of 11/24-11/27, suggesting that the Chla enhancement maintained for $\sim 2$ weeks, consistent with earlier findings [Babin et al., 2004].

[18] We attributed the initial Chla increase of 0.08 to $0.14 \mathrm{mg} / \mathrm{m}^{3}$ to upward transport of the deep Chla maxima and the delayed Chla increase of 0.14 to $0.37 \mathrm{mg} / \mathrm{m}^{3}$ to new production. It was estimated that new production contributed ca. $79 \%$ to the total production, about $10 \%$ greater than that from Hurricane Ivan in the Gulf of Mexico [Walker et al., 2005]. To assess Lingling's contribution to carbon fixation, a primary production model [Behrenfeld and Falkowski, 1997] was used with the observed Chla and SST. Daily rate of carbon fixation for the bloom area increased from $215 \mathrm{mgC} / \mathrm{m}^{2} / \mathrm{d}$ before Lingling to $\sim 924 \mathrm{mgC} / \mathrm{m}^{2} / \mathrm{d}$ after Lingling's passage, and this 15 -day event had probably fixed $0.4 \mathrm{Mt}$ of carbon. These numbers are lower than those estimated for typhoon Kai-Tak in the northeastern SCS that did not distinguish CDOM from Chla [Lin et al., 2003]. Note that these numbers are conservative estimates because the peak Chla maintained for about three days (the area was not easy to estimate due to heavy cloud cover, however). The contribution of Lingling to oceanic carbon fixation was significant.

\section{Conclusions}

[19] Our results presented the first case for typhooninduced enhancement of primary production over the central SCS during winter monsoon. There are several novel aspects that distinguish this work from other studies on typhoon- or hurricane-induced ocean responses. First, maximum cooling was about $11^{\circ} \mathrm{C}$ and the impacted area was several times larger than those reported earlier for the northern SCS. This is mainly attributed to the pre-existing cyclonic circulation, driven by the prevailing northeast monsoon in this season. Second, the color changes were separated explicitly into Chla and CDOM/detritus using a new algorithm, and attributed to changes in both Chla and $\mathrm{CDOM} /$ detritus due to mixing and new production. Finally, the regional $a_{\mathrm{ph}}^{*}(443)$ led to more realistic Chla estimates from satellite measurements.

[20] Hence, these unambiguous results, together with earlier reports for the northern SCS, suggest that typhoons indeed contributed to local primary production and carbon fixation through nutrient pumping to the surface. Because numerous hurricanes/typhoons occur every year in the global ocean, their significance to global primary production deserves more consideration, and further investigation using the most updated bio-optical models is advocated in order to better quantify their contribution and to reduce uncertainty in the global carbon budget.

[21] Acknowledgments. This research was funded by NSF-China (40521003, 40706041), MOST of China (2006AA09A302), National Key Technology R \& D Program of China (2006BAB19B01), the 111 Program 
in University, and US NASA (NNS04AB59G). I. J. Hodgkiss is acknowledged for his assistance in preparing the manuscript.

\section{References}

Babin, S. M., J. A. Carton, T. D. Dickey, and J. D. Wiggert (2004), Satellite evidence of hurricane-induced phytoplankton blooms in an oceanic desert, J. Geophys. Res., 109, C03043, doi:10.1029/2003JC001938.

Behrenfeld, M. J., and P. G. Falkowski (1997), Photosynthetic rates derived from satellite based chlorophyll concentration, Limnol. Oceanogr., 42, $1-20$.

Hoge, F. E., and P. E. Lyon (2002), Satellite observation of chromophoric dissolved organic matter (CDOM) variability in the wake of hurricanes and typhoons, Geophys. Res. Lett., 29(19), 1908, doi:10.1029/ 2002GL015114.

Hong, H., J. Wu, S. Shang, and C. Hu (2005), Absorption and fluorescence of chromophoric dissolved organic matter in the Pearl River Estuary, South China Sea, Mar. Chem., 97, 78-89.

$\mathrm{Hu}$, C. M., and F. E. Muller-Karger (2007), Response of sea surface properties to Hurricane Dennis in the eastern Gulf of Mexico, Geophys. Res. Lett., 34, L07606, doi:10.1029/2006GL028935.

Hu, C., Z. Lee, F. E. Muller-Karger, K. L. Carder, and J. J. Walsh (2006), Ocean color reveals phase shift between marine plants and yellow substance, IEEE Trans. Geosci. Remote Sens., 3, 262-266.

Lee, Z. P., K. L. Carder, and R. A. Arnone (2002), Deriving inherent optical properties from water color: A multiband quasi-analytical algorithm for optically deep waters, Appl. Opt., 41, 5755-5772.

Li, L., R. S. Wu, and X. G. Guo (2000), Seasonal circulation in the South China Sea: A TOPEX/POSEIDON satellite altimetry study, Acta Oceanol. Sin., 22, 13-26.

Lin, I., W. T. Liu, C.-C. Wu, G. T. F. Wong, C. Hu, Z. Chen, W.-D. Liang, Y. Yang, and K.-K. Liu (2003), New evidence for enhanced ocean primary production triggered by tropical cyclone, Geophys. Res. Lett., 30(13), 1718, doi:10.1029/2003GL017141.
Luis, A. J., and H. Kawamura (2000), Wintertime wind forcing and sea surface cooling near the south India tip observed using NSCAT and AVHRR, Remote Sens. Environ., 73, 55-64.

Mann, K. H., and J. R. N. Lazier (1996), Dynamics of Marine Ecosystems: Biological-Physical Interactions in the Ocean, 2nd ed., Blackwell Sci., Cambridge, Mass.

Price, J. F. (1981), Upper ocean response to a hurricane, J. Phys. Oceanogr., 11, $153-175$.

Price, J. F., T. B. Sanford, and G. Z. Forristall (1994), Forced stage response to a moving hurricane, J. Phys. Oceanogr., 24, 233-260.

Shay, L. K., G. J. Goni, and P. G. Black (2000), Effects of a warm oceanic feature on Hurricane Opal, Mon. Weather Rev., 128, 1366-1383.

Walker, N. D., R. R. Leben, and S. Balasubramanian (2005), Hurricaneforced upwelling and chlorophyll a enhancement within cold-core cyclones in the Gulf of Mexico, Geophys. Res. Lett., 32, L18610, doi:10.1029/2005GL023716.

Wu, J., H. Hong, S. Shang, M. Dai, and Z. Lee (2007), Variation of phytoplankton absorption coefficients in the northern South China Sea during spring and autumn, Biogeosci. Discuss., 4, 1555-1584.

Zheng, G. M., and D. L. Tang (2007), Offshore and nearshore chlorophyll increases induced by typhoon winds and subsequent terrestrial rainwater runoff, Mar. Ecol. Prog. Ser., 333, 61-74.

D. Chen, S. Shang, S. Shang, F. Sun, J. Wu, and C. Zhang, State Key Laboratory of Marine Environmental Science, Xiamen University, Xiamen 361005, China. (slshang@gmail.com)

C. Hu, College of Marine Sciences, University of South Florida, St. Petersburg, FL 33701, USA.

L. Li and Y. Qiu, Third Institute of Oceanography, State Oceanic Administration, Xiamen 361005, China.

X. Ning, State Key Laboratory of Satellite Ocean Environment Dynamic Processes, State Oceanic Administration, Hangzhou 310012, China. 